\title{
Lung transplantation in the elderly: Influence of age, comorbidities, underlying disease, and extended criteria donor lungs
}

\author{
Jonas P. Ehrsam, MD, ${ }^{\mathrm{a}}$ Christian Benden, MD,${ }^{\mathrm{b}}$ Burkhardt Seifert, MD,${ }^{\mathrm{c}}$ Isabelle Opitz, MD, \\ Didier Schneiter, MD, ${ }^{a}$ Walter Weder, MD, ${ }^{a}$ and Ilhan Inci, MD, FCCP
}

\section{ABSTRACT}

Objective: As large registries show an increased risk for lung transplant recipients aged 60 years or more, few single centers report favorable outcomes for carefully selected older recipients without providing essential details. The purpose of our study was to determine variables that influence survival in the elderly.

Methods: All adult bilateral first lung transplants between January 2000 and December 2014 were divided in 2 groups: those aged less than 60 years $(\mathrm{N}=223)$ and those aged 60 years or more $(\mathrm{N}=83)$. The Charlson-Deyo Index determined recipient comorbidities. The Oto Donor Score assessed donor lung quality.

Results: Recipients aged 60 years or more had a significant lower median survival compared with their younger counterparts (48 vs 112 months, respectively, $P<.001)$. Recipient age was as an exponentially increasing univariate risk factor for mortality. By adjusting for variables in multivariate analysis, this trend was nonsignificant. The displacing variables were idiopathic pulmonary fibrosis (hazard ratio [HR], 1.5; 95\% confidence interval [CI], 1.0-2.2), Charlson-Deyo Index 2 or greater (HR, 1.3; 95\% CI, 1.0-1.8), systemic hypertension (HR, 1.7; 95\% CI, 1.2-2.6), gastroesophageal reflux (HR, 1.9; 95\% CI, 1.1-3.1), diverticulosis (HR, 1.7; 95\% CI, 1.0-2.7), and an Oto Donor Score 8 or greater (HR, $1.5 ; 95 \%$ CI, 1.1-2.0). All of these risk factors were significantly more likely to occur in recipients aged 60 years or more, except for a tendency for high Charlson-Deyo Index.

Conclusions: The comorbidity profile, underlying disease, and donor lung quality appear to be more important than age in reducing long-term survival. Older age serves as a marker for a complex constellation of factors that might be considered the relative or absolute contraindication to lung transplantation rather than age, per se. (J Thorac Cardiovasc Surg 2017;154:2135-41)

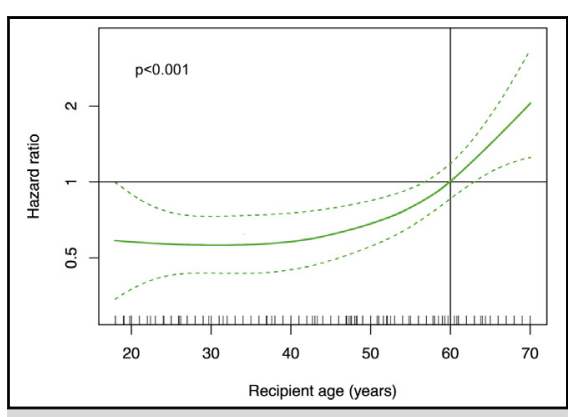

Worse survival in the elderly due to several risk factors.

\section{Central Message}

Older age is not predominantly reducing longterm survival per se, but the complex constellation of factors that are often associated with it

\section{Perspective}

Our study demonstrates that consideration of the comorbidity profile, the underlying disease and the marginality of the donor lung are more important than age per se to optimize the outcome in elderly recipients. We recommend to further identify and specify these factors in this special group that is increasingly referred for transplantation.

See Editorial Commentary page 2142.

\footnotetext{
From the ${ }^{\mathrm{a}}$ Department of Thoracic Surgery and ${ }^{\mathrm{b}}$ Division of Pulmonary Medicine, Zurich University Hospital; and ${ }^{\mathrm{c}}$ Epidemiology, Biostatistics and Prevention Institute, University of Zurich, Zurich, Switzerland.

Read at the International Society for Heart \& Lung Transplantation, 35th Annual Meeting and Scientific Sessions, Nice, France, April 15-18, 2015.

Received for publication June 9, 2016; revisions received June 15, 2017; accepted for publication July 21, 2017; available ahead of print Aug 18, 2017.

Address for reprints: Ilhan Inci, MD, FCCP, University Hospital, Department of Thoracic Surgery, Raemisstrasse 100, Zurich 8091, Switzerland (E-mail: ilhan. inci@usz.ch).

$0022-5223 / \$ 36.00$

Copyright (c) 2017 by The American Association for Thoracic Surgery

http://dx.doi.org/10.1016/j.jtcvs.2017.07.032
}

Because of demographic changes, there is an increasing number of older patients undergoing lung transplantation (LTx). The number of LTx recipients aged 60 years or

Scanning this QR code will take you to the article title page. 


\section{Abbreviations and Acronyms \\ CI $=$ confidence interval \\ Group $<60=$ recipients aged $<60$ years \\ Group $60^{+}=$recipients aged $\geq 60$ years \\ HR $=$ hazard ratio \\ IPF $=$ interstitial pulmonary fibrosis \\ ISHLT = International Society for Heart and Lung Transplantation \\ LTx = lung transplantation \\ UNOS = United Network for Organ Sharing}

more increased worldwide from more than $20 \%$ in the year 2000 to more than $40 \%$ in $2012 .{ }^{1}$

The early published guidelines of the International Society for Heart and Lung Transplantation (ISHLT) in 1998 suggested 60 years of age to be the upper age limit for bilateral LTx because of "a significantly worse survival rate" as shown in the ISHLT Registry. ${ }^{2}$ On the basis of growing experience, the 2006 guidelines adapted the statement of age more than 65 years to be a "relative contraindication" for LTx resulting in "less optimal survival, likely due to comorbidities." 3 In 2015, no recommendation of a fixed upper age limit was given; however, it is stated "increasing age generally is associated with comorbid conditions that are either absolute or relative contraindications." ${ }^{4}$

Although the current ISHLT $^{5}$ and United Network for Organ Sharing (UNOS) ${ }^{6}$ registries continue to show a significantly increasing risk for LTx recipients aged 60 years or more, some single-center reports indicate that carefully selected older LTx candidates might have similar survival as younger recipients. $^{7-10}$ However, appropriate selection criteria for these recipients are lacking. In this study, we identify variables that influence survival in the elderly by comparing recipients aged less than 60 years and 60 or more years.

\section{PATIENTS AND METHODS}

We performed a retrospective cohort study in all recipients who underwent bilateral LTx from January 2000 to December 2014, with a survival follow-up of November 8, 2016. Pediatric recipients and retransplants were excluded. Patients were divided into 2 groups based on age at transplantation: Group $<60$ : aged less than 60 years $(\mathrm{N}=223)$, Group $60^{+}$: aged 60 years or more $(\mathrm{N}=83)$, for an optimal illustration of our sample size in regard to comparison with already published studies and consensus articles. We used electronic medical records to extract preoperative, intraoperative, and postoperative parameters for every individual recipient. Each postoperative event was observed for 3 months. Recipient cause of death also was evaluated. The corresponding donor data were retrieved using electronic donor records.

\section{Definition of Charlson-Deyo Index and Oto Donor Score}

Pretransplant recipient comorbidities were collected mainly on the basis of relative contraindications from ISHLT guidelines published in $2006^{3}$ and
2015. ${ }^{4}$ To estimate the impact of multiple recipient pretransplant comorbidities, the age-independent Charlson-Deyo Index ${ }^{11}$ was used. This index considers 19 comorbid conditions (ranging from 1 to 6 points), of which 1 point was always reserved by the chronic pulmonary disease in each of our recipients.

Oto Donor Score ${ }^{12}$ was used to estimate the quality of donor lungs, including 5 extended donor criteria based on the recent ISHLT Consensus Report $^{13}$ : age, smoking history, chest $\mathrm{x}$-ray, secretion in bronchoscopy, and pulmonary arterial oxygen tension/fraction of inspired oxygen ratio.

\section{Statistical Analysis}

Statistical analysis was performed with R 3.3.2 (R Core Team, 2016), IBM SPSS Statistics 23.0 (IBM Corp, 2015, Armonk, NY), and Stata 13.1 (StataCorp LP, College Station, Tex). Categoric variables were compared by chisquare test or Fisher exact test for expected frequencies less than 5. Continuous variables were analyzed by the Mann-Whitney test. Survival was calculated by the Kaplan-Meier method and compared with log-rank test. Cox regression was used to assess risk factors for mortality. First, every variable was checked with a univariate (enter) model. Variables with a $P$ value less than $.2^{14}$ were tested in a multivariable stepwise backward Cox regression model. The number of factors introduced into the final multivariable model was calculated by considering sample size and number of occurring deaths. ${ }^{15}$ To confirm that variables show a stable significance, they had to be frequent in number. Linear regression was used to test collinearity between variables. A variance inflation factor greater than 5 and a tolerance less than 0.2 was defined as indicating a collinearity problem. Separate univariate and generalized additive (gam) Cox regressions for mortality with flexible smoothing in the R-package $\mathrm{mcv}^{16}$ were conducted to analyze the effect of recipient age as a continuous variable on mortality. The local research ethics review committee approved the study (KEK-ZH-Nr.2013-0624).

\section{RESULTS}

Pretransplant recipient and donor characteristics are presented in Table 1. Interstitial pulmonary fibrosis (IPF) and emphysema were the 2 frequent underlying diseases in Group $60^{+}$, whereas it was cystic fibrosis in Group $<60$.

Recipients in Group $60^{+}$significantly more often had 2 or more comorbidities in general $(53 \%$ vs $31 \%)$ and diverticulosis, gastroesophageal reflux, systemic hypertension, peripheral vascular disease, postinterventional coronary diseases, and transient cerebrovascular incident in particular. The Charlson-Deyo Index ${ }^{11}$ also showed a nonsignificant trend of more comorbidities in the older group.

A significantly higher number of recipients in Group $60^{+}$ received grafts that did not satisfy 2 or more of the 5 ideal donor criteria according to the ISHLT document. ${ }^{13}$ This is in line with the derived Oto Donor Score, ${ }^{12}$ which also showed a significantly higher amount of more extended donor grafts in Group60 $0^{+}$.

As shown in Table 2, intensive care unit stay was significantly longer in Group60 $0^{+}$, whereas days of intubation and intraoperative extracorporeal membrane oxygenation use were comparable. A cytomegalovirus high-risk constellation (recipient: negative, donor: positive) was significantly more frequent in Group $60^{+}$, affecting more than half of the recipients. Postoperative atrial fibrillation, abdominal complications, and delirium occurred more significantly in Group $60^{+}$. 
TABLE 1. Pretransplant recipient and donor characteristics

\begin{tabular}{|c|c|c|c|}
\hline \multicolumn{4}{|c|}{ Recipient characteristics } \\
\hline Variable & Group $<60$ & Group60 $^{+}$ & $P$ value \\
\hline $\mathrm{N}$ & 223 & 83 & \\
\hline Age, y, median (range) & $44(18-59)$ & $63(60-70)$ & \\
\hline Male gender & $115(51.6 \%)$ & $50(60.2 \%)$ & .2 \\
\hline \multicolumn{4}{|l|}{ Diagnosis } \\
\hline $\mathrm{CF}$ & $92(41.3 \%)$ & 0 & $<.001$ \\
\hline Emphysema & $61(27.4 \%)$ & $33(39.8 \%)$ & .04 \\
\hline IPF & $36(16.1 \%)$ & $35(42.2 \%)$ & $<.001$ \\
\hline IPAH & $14(6.3 \%)$ & $3(3.6 \%)$ & .6 \\
\hline Other & $20(9.0 \%)$ & $12(14.5 \%)$ & \\
\hline $\mathrm{mPAP}>25 \mathrm{~mm} \mathrm{Hg}$ & $131(58.7 \%)$ & $50(60.2 \%)$ & .8 \\
\hline Waitlist time (d), median (range) & $175(0-1175)$ & $155(2-914)$ & .5 \\
\hline \multicolumn{4}{|l|}{ Comorbidities in Charlson-Deyo Index } \\
\hline Postinterventional coronary disease & $11(4.9 \%)$ & $13(15.7 \%)$ & .002 \\
\hline Congestive heart failure & $20(9.0 \%)$ & $7(8.4 \%)$ & .9 \\
\hline Peripheral vascular disease & $3(1.3 \%)$ & $5(6.0 \%)$ & .02 \\
\hline \multicolumn{4}{|l|}{ Diabetes mellitus } \\
\hline No end-organ damage & $44(19.7 \%)$ & $7(8.4 \%)$ & .02 \\
\hline End-organ damage & $1(0.4 \%)$ & 0 & .5 \\
\hline Mild liver disease & $13(5.8 \%)$ & $5(6.0 \%)$ & .9 \\
\hline Renal impairment & $8(3.6 \%)$ & $7(8.4 \%)$ & .1 \\
\hline Transient cerebrovascular incident & 0 & $2(2.4 \%)$ & .02 \\
\hline \multicolumn{4}{|l|}{ Other comorbidities } \\
\hline $\mathrm{BMI} \geq 30 \mathrm{~kg} / \mathrm{m}^{2}$ & $16(7.2 \%)$ & $6(7.2 \%)$ & .9 \\
\hline Systemic hypertension & $27(12.1 \%)$ & $27(32.5 \%)$ & $<.001$ \\
\hline Osteoporosis & $53(23.8 \%)$ & $24(28.9 \%)$ & .4 \\
\hline Diverticulosis & $12(5.4 \%)$ & $24(28.9 \%)$ & $<.001$ \\
\hline Gastroesophageal reflux & $12(5.4 \%)$ & $13(15.7 \%)$ & .004 \\
\hline Critical situation (eg, MV, ECMO, ICU) & $26(11.7 \%)$ & $3(3.6 \%)$ & .05 \\
\hline Accumulated number of comorbidities (of 14 factors above) median (range) & $1(0-5)$ & $2(0-5)$ & $<.001$ \\
\hline$\geq 1$ & $155(69.5 \%)$ & $67(80.7 \%)$ & .05 \\
\hline$\geq 2$ & $70(31.4 \%)$ & $44(53.0 \%)$ & .001 \\
\hline$\geq 3$ & $18(8.1 \%)$ & $21(25.3 \%)$ & $<.001$ \\
\hline Charlson-Deyo Index median (range) & $1(1-5)$ & $1(1-5)$ & .2 \\
\hline$\geq 2$ & $85(38.1)$ & $37(44.6)$ & .3 \\
\hline$\geq 3$ & $23(10.3)$ & $12(14.5)$ & .3 \\
\hline \multicolumn{4}{|l|}{ Donor characteristics } \\
\hline No. of extended donor criteria, median (range) & $1(0-4)$ & $2(0-5)$ & .03 \\
\hline$\geq 2$ & $91(40.8 \%)$ & $47(56.6 \%)$ & .01 \\
\hline$\geq 3$ & $26(11.7 \%)$ & $17(20.5 \%)$ & .05 \\
\hline Oto Donor Score median (range) & $6(0-12)$ & $7(0-13)$ & .003 \\
\hline$\geq 8$ & $74(33.2 \%)$ & $41(49.4 \%)$ & .01 \\
\hline$\geq 9$ & $49(22.0 \%)$ & $32(38.6 \%)$ & .003 \\
\hline
\end{tabular}

$C F$, Cystic fibrosis; $I P F$, idiopathic pulmonary fibrosis; $I P A H$, idiopathic pulmonary arterial hypertension; $m P A P$, mean pulmonary artery pressure; $B M I$, body mass index; $M V$, mechanical ventilation; $E C M O$, extracorporeal membrane oxygenation; $I C U$, intensive care unit.

During the study period, a total of 167 recipients died: $109(49 \%)$ and $58(70 \%)$ in Group $<60$ and Group60 $0^{+}$, respectively. Table 3 shows the causes of death. Infections leading to sepsis or multiorgan failure were the most common factors in both groups. Death due to cardiac failure tended to be higher in Group60 $0^{+}$.
Short-term survival was comparable between Group $<60$ and Group $60^{+}$(2-year survival \pm standard error $80.7 \% \pm 2.6 \%$ vs $73.5 \% \pm 4.8 \%$, respectively), whereas long-term survival showed a significant disadvantage for recipients aged 60 years or more (log-rank $P<.001$ ) (Figure 1). Median follow up was 9.3 years 
TABLE 2. Perioperative and postoperative recipient characteristics

\begin{tabular}{|c|c|c|c|}
\hline Variable & Group $<60$ & Group60 $^{+}$ & $P$ value \\
\hline $\mathrm{N}$ & 223 & 83 & \\
\hline \multicolumn{4}{|l|}{ Perioperative characteristics } \\
\hline ECMO use & $105(47.1)$ & $41(49.4)$ & .7 \\
\hline CMV high-risk constellation & $86(38.1 \%)$ & $47(56.6 \%)$ & .004 \\
\hline ICU stay d, median (range) & $3(1-163)$ & $5(1-147)$ & .001 \\
\hline Intubation $\mathrm{d}$, median (range) & $1(0-163)$ & $1(0-147)$ & .4 \\
\hline \multicolumn{4}{|l|}{ Complications within $3 \mathrm{mo}$} \\
\hline Graft failure within $30 \mathrm{~d}$ & $6(2.7 \%)$ & $2(2.4 \%)$ & 1.0 \\
\hline $\begin{array}{l}\text { Critical illness } \\
\text { polyneuropathy/myopathy }\end{array}$ & $17(7.6 \%)$ & $9(10.8 \%)$ & .4 \\
\hline Cerebrovascular accident & $7(3.1 \%)$ & $3(3.6 \%)$ & 1.0 \\
\hline Atrial fibrillation & $43(19.3 \%)$ & $33(39.8 \%)$ & $<.001$ \\
\hline Dialysis & $27(12.1 \%)$ & $11(13.3 \%)$ & .8 \\
\hline Abdominal complication & $20(9.0 \%)$ & $15(18.1 \%)$ & .03 \\
\hline Phrenic nerve injury & $5(2.2 \%)$ & $1(1.2 \%)$ & 1.0 \\
\hline MOF & $6(2.7 \%)$ & $4(4.8 \%)$ & .5 \\
\hline ARDS & $10(4.5 \%)$ & $2(2.4 \%)$ & .5 \\
\hline Hemothorax & $40(17.9 \%)$ & $13(15.7 \%)$ & .6 \\
\hline Primary graft dysfunction & $22(9.9 \%)$ & $12(14.5 \%)$ & .3 \\
\hline Reintubation & $21(9.4 \%)$ & $10(12.0 \%)$ & 6 \\
\hline Postoperative tracheotomy & $45(20.2 \%)$ & $22(26.5 \%)$ & .2 \\
\hline Intrathoracic reoperation & $61(27.4 \%)$ & $25(30.1 \%)$ & .6 \\
\hline Delirium & $9(4.0 \%)$ & $14(16.9 \%)$ & $<.001$ \\
\hline \multicolumn{4}{|c|}{ Post-transplant infections within $3 \mathrm{mo}$} \\
\hline Bacterial & $73(32.7 \%)$ & $32(38.6 \%)$ & .3 \\
\hline Lung infection & $56(25.1 \%)$ & $25(30.1 \%)$ & .4 \\
\hline Organism bacteremia & $20(9.0 \%)$ & $8(9.6 \%)$ & .9 \\
\hline Sepsis & $9(4.0 \%)$ & $5(6.0 \%)$ & .5 \\
\hline $\begin{array}{l}\text { Clostridium difficile } \\
\text { diarrhea }\end{array}$ & $10(4.5 \%)$ & $1(1.2 \%)$ & .3 \\
\hline Fungal & $52(23.3 \%)$ & $15(18.2 \%)$ & .3 \\
\hline Viral & $15(6.7 \%)$ & $7(8.4 \%)$ & 6 \\
\hline CMV reactivation & $5(2.2 \%)$ & $1(1.2 \%)$ & 1.0 \\
\hline
\end{tabular}

$E C M O$, Extracorporeal membrane oxygenation; $C M V$, cytomegalovirus; $I C U$, intensive care unit; $M O F$, multiorgan failure; $A R D S$, acute respiratory distress syndrome.

(95\% confidence interval, 8.3-10.4) in Group $<60$ and 4.0 years $(95 \%$ confidence interval, $2.9-5.1)$ in Group $60^{+}$. No recipients were lost to follow-up.

Recipient age was revealed as an exponentially increasing univariate risk factor for mortality $(P<.001)$ (Figure 2,A), with a duplication of the risk between 60 and 70 years of age.

By adjusting for variables and by smoothing the nonlinear effect of recipient age on mortality in multivariate analysis $(P=.2)$ (Table 4$)$, the risk trend of increasing recipient age was nonsignificant (Figure 2, B). The displacing variables are listed in Table 4. Among underlying lung diseases, IPF was found to be a risk factor for mortality. Charlson-Deyo Index of 2 or greater was as a risk factor, indicating a potential risk for a recipient with a single underlying comorbidity, because 1 point was always assessing the underlying lung disease. However, these
TABLE 3. Cause of recipient death

\begin{tabular}{lrrr}
\hline & \multicolumn{1}{c}{ Group $<\mathbf{6 0}$} & \multicolumn{1}{c}{ Group60 } & P value \\
\hline $\mathrm{N}$ & $109 / 223(48.9 \%)$ & $58 / 83(69.9 \%)$ & \\
Infection leading & $37(33.9 \%)$ & $19(32.8 \%)$ & .9 \\
$\quad$ to sepsis/MOF & & & \\
Cardiac failure & $3(2.8 \%)$ & $6(10.3 \%)$ & .04 \\
Renal failure & $2(1.8 \%)$ & $1(1.7 \%)$ & \\
Hemorrhagic shock & $3(2.8 \%)$ & $3(5.2 \%)$ & \\
Intracranial bleeding & $3(2.8 \%)$ & $3(5.2 \%)$ & \\
Malignancy & $15(13.8 \%)$ & $9(15.5 \%)$ & .8 \\
\hline Graft failure & $34(31.2 \%)$ & $14(24.1 \%)$ & .3 \\
Bowel perforation & $9(8.3 \%)$ & $2(3.5 \%)$ & .2 \\
\hline Other & $1(0.9 \%)$ & 0 & \\
\hline Not available & $1(0.9 \%)$ & $1(1.7 \%)$ & \\
BOS at death & $40(36.7 \%)$ & $16(27.6 \%)$ & .3 \\
\hline Unknown & $6(5.5 \%)$ & $6(10.3 \%)$ & \\
\hline
\end{tabular}

MOF, Multiorgan failure; $B O S$, bronchiolitis obliterans syndrome.

underlying comorbidities were not frequent and stable enough to become independent multivariate risk factors. Among other comorbidities, systemic hypertension, diverticulosis, and gastroesophageal reflux were independent risk factors, without association with the Charlson-Deyo Index. Extended donor lungs started to be a risk at an Oto Donor Score of 8 or greater. No collinearity was observed among all variables in the multivariate model.

\section{DISCUSSION}

This study demonstrates that older age is not per se predominantly reducing long-term survival after LTx, but a complex constellation of factors that are more often associated with advanced age, namely, the comorbidity profile, underlying disease, and extended donor lungs.

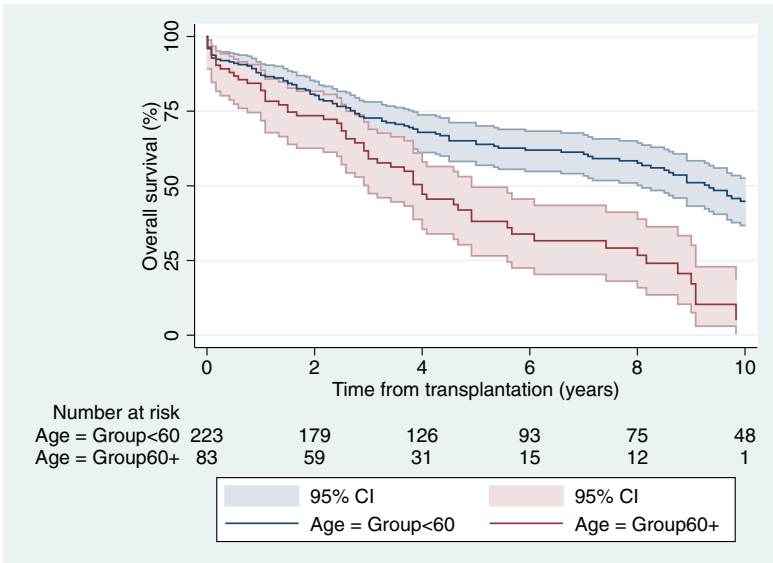

FIGURE 1. Kaplan-Meier survival analysis showing a significant difference between the 2 groups. Group $<60$, recipients aged less than 60 years $(\mathrm{N}=223)$; Group $60^{+}$, recipients aged 60 years or more $(\mathrm{N}=83)$. $C I$, Confidence interval. 

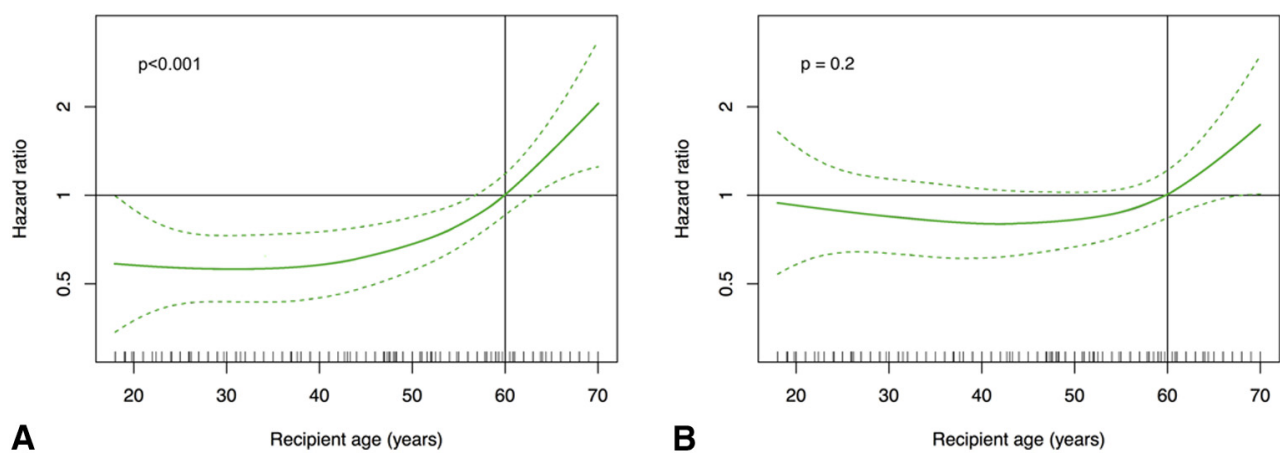

FIGURE 2. A, Univariate penalized spline regression showing a significant risk for mortality for increasing recipient age $(P<.001)$. B, Multivariable penalized spline regression showing a nonsignificant trend for recipient age $(P=.2)$ after adjusting for IPF, Charlson-Deyo Index 2 or greater, diverticulosis, gastroesophageal reflux, and Oto Donor Score 8 or greater.

Although short-term survival was comparable between our age groups, long-term survival was significantly worse in older recipients. Moreover, we demonstrated an exponentially increasing risk for mortality for advancing recipient age, if no adjustment for the comorbidity profile, underlying disease, and quality of the donor lung was made. This clear disadvantageous outcome is comparable with the current ISHLT Registry ${ }^{1,5}$ and the UNOS Reports $^{6,18}$ and was also supported by the Toronto Group $^{17}$ and the UNOS report. ${ }^{18}$ In contrast, other singlecenter studies ${ }^{7-10}$ that used "carefully selected" older recipients demonstrated favorable intermediate and longterm outcomes (Table 5); however, these studies failed to list their detailed selection criteria for this success.

IPF generally is known to reduce post-transplant survival $^{5}$ and revealed as a risk factor in our study as well. IPF was the predominant underlying disease in our older recipients, which was higher than in previous studies (Table 5).

Considering multiple comorbidities, more than half of our recipients aged 60 years or more had 2 or more comorbidities, which was remarkably more than in the

TABLE 4. Multivariate analysis of risk factors for mortality

\begin{tabular}{lrccc}
\multicolumn{1}{c}{ Variable } & N & HR & 95\% CI & $\boldsymbol{P}$ value \\
\hline Recipient age (smooth) & & - & - & .2 \\
IPF diagnosis & 71 & 1.5 & $1.0-2.2$ & .04 \\
Charlson-Deyo Index $\geq 2$ & 122 & 1.3 & $1.0-1.8$ & .05 \\
Systemic hypertension & 54 & 1.7 & $1.2-2.6$ & .007 \\
Diverticulosis & 36 & 1.7 & $1.0-2.7$ & .03 \\
Gastroesophageal reflux & 25 & 1.9 & $1.1-3.1$ & .02 \\
Oto Donor Score $\geq 8$ & 115 & 1.5 & $1.1-2.0$ & .01 \\
\hline
\end{tabular}

The following variables were no multivariate risk factors: emphysema diagnosis, idiopathic pulmonary arterial hypertension diagnosis, cytomegalovirus high-risk constellation, body mass index $\geq 30 \mathrm{~kg} / \mathrm{m}^{2}$, osteoporosis, all separate variables in the Charlson-Deyo Index, and critical situation (eg, mechanical ventilation, extracorporeal membrane oxygenation, and intensive care unit). $H R$, Hazard ratio; $C I$, confidence interval; $I P F$, idiopathic pulmonary fibrosis. younger group. By accumulating comorbidities with the Charlson-Deyo Index,${ }^{11}$ recipients with a single underlying comorbidity were already at a significantly increased risk. Other studies that have focused on older age provided incomplete comorbidity data, which obviates a reasonable

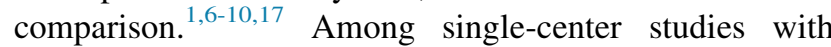
favorable outcomes in the elderly, the California Group ${ }^{8}$ reported that 1 comorbidity was tolerated in their group aged 65 years or more, which might be due to a stricter selection of candidates compared with our current series. The Toronto Group ${ }^{17}$ demonstrated a less favorable outcome in their 42 recipients aged more than 60 years; 4 cases of systemic hypertension were reported of, which 2 also had diabetes. Again, it appears that stricter selection criteria might have been applied compared with our series.

Among the comorbidities, systemic hypertension, diverticulosis, and gastroesophageal reflux were independent risk factors for mortality and each represented even a higher risk impact than the underlying diagnosis of IPF. Our older recipient group more often had all 3 of them.

Systemic hypertension as a pretransplant risk factor is remarkable, because it was only reported from a single study using UNOS Registry data in 821 recipients with pulmonary fibrosis. ${ }^{19}$ In another study on more than 8000 recipients, systemic hypertension was not a risk factor, ${ }^{20}$ and ISHLT $^{5}$ reports do not list it. A recent meta-analysis ${ }^{21}$ has shown that systemic hypertension was a risk factor for postoperative atrial arrhythmias and therefore had prognostic implications for length of hospital stay and overall survival. In our recipients aged less than 60 years and 60 years or more, $21 \%(\mathrm{~N}=9)$ and $42 \%(\mathrm{~N}=14)$ with systemic hypertension were affected by postoperative arrhythmias. In addition, pretransplant systemic hypertension might aggravate itself faster after transplant because of the side effect of immunosuppression treatment with calcineurin inhibitors than in previously healthy recipients and therefore leads to general organ damage earlier.

Acute diverticulitis is associated with a high mortality rate in immunosuppressed patients, and the rate of 
TABLE 5. Comparison of published Kaplan-Meier survival and idiopathic pulmonary fibrosis in the elderly

\begin{tabular}{lrrccc}
\hline & Age, $\mathbf{y}$ & $\mathbf{N}$ & $\mathbf{3} \mathbf{y}(\%)$ & $\mathbf{5} \mathbf{y}(\%)$ & IPF $\%$ \\
\hline Current series & $60-65$ & 61 & 59 & 41 & 41 \\
& $>65$ & 22 & 68 & 32 & 58 \\
ISHLT $^{1}$ & $60-65$ & 7342 & - & 46 & - \\
& $>65$ & 2014 & - & 38 & 50 \\
UNOS $^{18}$ & $60-69$ & 6021 & 63 & 48 & 41 \\
University of California $^{8}$ & $\geq 65$ & 50 & 74 & - & 58 \\
University of Pittsburgh $^{9}$ & $60-65$ & 43 & 63 & - & 23 \\
& $>65$ & 78 & 69 & - & 55 \\
& $\geq 60$ & 52 & 71 & 55 & 27 \\
University of Virginia $^{10}$ & $\geq 65$ & 16 & 91 & 91 & \\
& $\geq 60$ & 42 & - & 47 & 37 \\
Mayo Clinic $^{7}$ & $>60$ & 42 & - & 37 & 36 \\
\hline University of Toronto & \\
\hline
\end{tabular}

IPF, Idiopathic pulmonary fibrosis; ISHLT, International Society for Heart and Lung Transplantation; UNOS, United Network for Organ Sharing. *All restrictive diseases.

developing acute diverticulitis is significantly higher than the baseline. ${ }^{22}$ At our center, we recently reported an overall rate of diverticulitis of $4.5 \%$ after LTx. ${ }^{23}$ Progression of preexisting diverticulosis into diverticulitis has been shown to surpass this rate to up to $16 \% .^{24}$

Gastroesophageal reflux has been found to be strongly associated with secondary aspiration contributing to chronic lung allograft dysfunction. However, causal proof is still pending. ${ }^{25}$

Postinterventional coronary disease, congestive heart failure, peripheral vascular disease, diabetes mellitus, mild liver disease, and renal impairment were infrequent comorbidities in our series but reviled as a risk factor when combined in the Charlson-Deyo Index.

Postinterventional coronary artery disease was $16 \%$ more frequent in our older recipients along with a trend of more deaths due to cardiac failure. The Pittsburgh Group ${ }^{9}$ showed successful short-term survival in their patients aged 60 to 65 years and more than 65 years, of whom $12 \%$ and $26 \%$ had coronary artery disease, respectively. For mild to moderate coronary artery disease only, no affection of overall long-term outcome was found in 539 recipients at the Duke University. ${ }^{26}$

Bacterial infection was the predominant cause of death in both age groups in our study. Previous studies have identified bacterial infections as the most common cause of death in older LTx recipients. ${ }^{8,9,17}$ On the other hand, others have not shown increased rates of post-LTx infections in older recipients ${ }^{10}$ or even a certain protection from infection. ${ }^{20}$ Death from bronchiolitis obliterans syndrome was comparable with other studies. ${ }^{6,9,20}$

In our study, significantly more extended criteria donor lungs were used in older recipients. We assessed the risk of donor lung quality with the Oto Donor Score ${ }^{12}$ and found a score of 8 or more points to be an independent risk factor. Half of the recipients in our older group were exposed to the risk of an 8-point or greater graft. Of note, other centers reported reduced outcome with an Oto Donor Score of 7 points $^{12}$ or less. ${ }^{27}$ The impact of donor quality in older recipients has rarely been investigated. Only the California Group, ${ }^{8}$ which reported successful outcome in the elderly, showed that $46 \%$ of their recipients aged more than 65 years received extended criteria donor lungs compared with $28 \%$ in their younger group. However, the extended criteria of these grafts were not further specified, making a comparison impossible.

\section{Study Limitations}

Our study has several limitations. It is a retrospective, small-volume, single-center study over more than a decade. Although the Charlson-Deyo Index is widely used, it might not have expressed the exact strength of the broad spectrum of comorbidities in LTx recipients. Also, the Oto Donor Score considers just a few simple parameters and has not been tested in large cohorts.

\section{CONCLUSIONS}

Old recipient age has been considered a relative or absolute contraindication to LTx in part because of progressively poorer survival. However, it is uncertain whether older age is the predominant risk factor per se. This study reveals that the comorbidity profile, underlying disease, and donor lung selection seem to be more important than age in reducing survival. Older age then serves as a marker for a complex constellation of factors that reduce long-term survival after LTx. Some of these factors may be correctable, and others are immutable. It is the constellation of factors that might be considered the relative or absolute contraindication to LTx rather than any one of them, including age, per se. Because LTx in the elderly is an ongoing controversial ethical challenge, we encourage other centers to help further identify and specify factors to optimize outcome.

\section{Conflict of Interest Statement}

Authors have nothing to disclose with regard to commercial support.

\section{References}

1. Yusen RD, Christie JD, Edwards LB, Kucheryavaya AY, Benden C, Dipchand AI, et al; International Society for Heart and Lung Transplantation. The Registry of the International Society for Heart and Lung Transplantation: Thirtieth Adult Lung and Heart-Lung Transplant Report-2013; focus theme: age. J Heart Lung Transplant. 2013;32:965-78.

2. Maurer JR, Frost AE, Estenne M, Higenbottam T, Glanville A. International guidelines for the selection of lung transplant candidates. The International Society of Heart and Lung Transplantation, the American Thoracic Society, the American Society of Transplant Physicians, the European Respiratory Society. J Heart Lung Transplant. 1998;17:703.

3. Orens JB, Estenne M, Arcasoy S, Conte JV, Corris P, Egan JJ, et al; Pulmonary Scientific Council of the International Society for Heart and Lung Transplantation. International guidelines for the selection of lung transplant 
candidates: 2006 update-a consensus report from the Pulmonary Scientific Council of the International Society for Heart and Lung Transplantation. J Heart Lung Transplant. 2006;25:745-55.

4. Weill D, Benden C, Corris PA, Dark JH, Davis RD, Keshavjee S, et al. A consensus document for the selection of lung transplant candidates: 2014An update from the Pulmonary Transplantation Council of the International Society for Heart and Lung Transplantation. J Heart Lung Transplant. 2015;34: $1-15$.

5. Yusen RD, Edwards LB, Dipchand AI, Goldfarb SB, Kucheryavaya AY, Levvey BJ, et al. The Registry of the International Society for Heart and Lung Transplantation: Thirty-third Adult Lung and Heart-Lung Transplant Report-2016; Focus Theme: Primary Diagnostic Indications for Transplant. International Society for Heart and Lung Transplantation. J Heart Lung Transplant. 2016;35:1170-84.

6. Genao L, Whitson HE, Zaas D, Sanders LL, Schmader KE. Functional status after lung transplantation in older adults in the post-allocation score era. Am J Transplant. 2013;13:157-66.

7. Tomaszek SC, Fibla JJ, Dierkhising RA, Scott JP, Shen KR, Wigle DA, et al. Outcome of lung transplantation in elderly recipients. Eur $J$ Cardiothorac Surg. 2011;39:726-31

8. Mahidhara R, Bastani S, Ross DJ, Saggar R, Lynch J, Schnickel GT, et al. Lung transplantation in older patients? J Thorac Cardiovasc Surg. 2008;135:412-20.

9. Vadnerkar A, Toyoda Y, Crespo M, Pilewski J, Mitsani D, Kwak EJ, et al. Age-specific complications among lung transplant recipients 60 years and older. J Heart Lung Transplant. 2011;30:273-81.

10. Smith PW, Wang H, Parini V, Zolak JS, Shen KR, Daniel TM, et al. Lung transplantation in patients 60 years and older: results, complications, and outcomes. Ann Thorac Surg. 2006;82:1835-41.

11. Deyo R, Cherkin DC, Ciol MA. Adapting a clinical comorbidity index for use with ICD-9-CM administrative databases. J Clin Epidemiol. 1992;45:613-9.

12. Oto T, Levvey BJ, Whitford H, Griffiths AP, Kotsimbos T, Williams TJ, et al. Feasibility and utility of a lung donor score: correlation with early post-transplant outcomes. Ann Thorac Surg. 2007;83:257-63.

13. Orens JB, Boehler A, de Perrot M, Estenne M, Glanville AR, Keshavjee S, et al. Pulmonary Council, International Society for Heart and Lung Transplantation. A review of lung transplant donor acceptability criteria. J Heart Lung Transplant. 2003;22:1183-200.

14. Sauerbrei W. The use of resampling methods to simplify regression models in medical statistics. J R Stat Soc Ser C Appl Stat. 1999;48:313-29.
15. Hosmer D, Lemeshow S. Applied Logistic Regression. 2nd ed. New York: Wiley; 2000.

16. Wood SN. Generalized Additive Models: An Introduction with R. London: Chapman and Hall/CRC; 2006.

17. Gutierrez C, Al-Faifi S, Chaparro C, Waddell T, Hadjiliadis D, Singer L, et al The effect of recipient's age on lung transplant outcome. Am J Transplant. 2007; 7:1271-7.

18. Hayanga AJ, Aboagye JK, Hayanga HE, Morrell M, Huffman L, Shigemura N, et al. Contemporary analysis of early outcomes after lung transplantation in the elderly using a national registry. J Heart Lung Transplant. 2015;34:182-8.

19. Meyer DM, Edwards LB, Torres F, Jessen ME, Novick RJ. Impact of recipient age and procedure type on survival after lung transplantation for pulmonary fibrosis. Ann Thorac Surg. 2005;79:950-8.

20. Weiss ES, Merlo CA, Shah AS. Impact of advanced age in lung transplantation: an analysis of United Network for Organ Sharing data. J Am Coll Surg. 2009;208: 400-9.

21. Fan J, Zhou K, Li S, Du H, Che G. Incidence, risk factors and prognosis of postoperative atrial arrhythmias after lung transplantation: a systematic review and meta-analysis. Interact Cardiovasc Thorac Surg. 2016;23:790-9.

22. Hwang SS, Cannom RR, Abbas MA, Etzioni D. Diverticulitis in transplant patients and patients on chronic corticosteroid therapy: a systematic review. Dis Colon Rectum. 2010;53:1699-707.

23. Vetter D, Schuurmans MM, Benden C, Clavien PA, Nocito A. Long-term follow-up of lung transplant recipients supports non-operative treatment of uncomplicated diverticulitis. Clin Transplant. 2016;30:1264-70.

24. Qasabian RA, Meagher AP, Lee R, Dore GJ, Keogh A. Severe diverticulitis after heart, lung, and heart-lung transplantation. J Heart Lung Transplant. 2004;23:845-9.

25. Gulack BC, Meza JM, Lin SS, Hartwig MG, Davis RD. Reflux and allograf dysfunction: is there a connection? Thorac Surg Clin. 2015;25:97-105.

26. Zanotti G, Hartwig MG, Castleberry AW, Martin JT, Shaw LK, Williams JB et al. Preoperative mild-to-moderate coronary artery disease does not affect long-term outcomes of lung transplantation. Transplantation. 2014;97:1079-85.

27. Porro GA, Valenza F, Coppola S, Froio S, Benazzi E, De Fazio N, et al. Use of the Oto lung donor score to analyze the 2010 donor pool of the Nord Italia Transplant program. Transplant Proc. 2012;44:1830-4.

Key Words: lung transplantation, elderly, comorbidity, extended criteria donors, older recipients, donor score 